\title{
Prevalence of Convergence Insufficiency-Type Symptomatology in Parkinson's Disease
}

\author{
Caroline Law, Estefania Chriqui, Marie-Jeanne Kergoat, Bernard-Simon Leclerc, \\ Michel Panisset, Elizabeth L. Irving, Ronald B. Postuma, Sylvain Chouinard, \\ Hélène Kergoat
}

\begin{abstract}
Background: Individuals with Parkinson's disease (PD) often present with visual symptoms (e.g., difficulty in reading, double vision) that can also be found in convergence insufficiency (CI). Our objective was to estimate the prevalence of CI-type visual symptomatology in individuals with PD, in comparison with controls. Methods: Participants $\geq 50$ years with $(n=300)$ and without $(n=300)$ PD were recruited. They were administered the Convergence Insufficiency Symptom Survey (CISS-15) over the phone. A score of $\geq 21$ on the CISS-15, considered positive for CI-type symptomatology, served as the cutoff. Data from individuals ( $n=87$ with, $n=94$ without PD) who were approached but who reported having a known oculovisual condition were analysed separately. Student's $t$ test and chi-square at the 0.05 level were employed for statistical significance. Results: A total of $29.3 \%$ of participants with versus $7.3 \%$ without PD presented with a score of $\geq 21$ on the CISS-15 ( $p=0.001)$. Of the participants having a known oculovisual condition, $39.1 \%$ with versus $19.1 \%$ without PD presented with a score of $\geq 21$ on the CISS-15 $(p=0.01)$. Conclusions: The prevalence of CI-type visual symptoms is higher in individuals with versus without PD whether or not they have a coexisting oculovisual condition. These results suggest that PD per se places individuals with the disease at greater risk of visual symptomatology. These results further underline the importance of providing regular eye exams for individuals with PD.
\end{abstract}

RÉSUMÉ: Prévalence de la symptomatologie de type insuffisance de convergence dans la maladie de Parkinson. Contexte: Les symptômes visuels (difficulté à lire, vision double), qu'on retrouve souvent dans l'insuffisance de convergence (IC), sont fréquents chez les patients atteints de la maladie de Parkinson (MP). Notre objectif était d'estimer la prévalence de la symptomatologie visuelle de type IC chez des patients atteints de la MP par rapport à des sujets témoins. Méthodologie : Nous avons recruté des sujets âgés de 50 ans ou plus, avec MP (n=300) et sans MP ( $\mathrm{n}=300)$. Ils ont répondu par téléphone au questionnaire Convergence Insufficiency Symptom Survey (CISS-15). Un score de 21 ou plus au CISS-15, qui est considéré comme positif pour la symptomatologie de type IC, a été utilisé comme seuil de coupe. Les données des sujets qui ont été contactés et qui rapportaient avoir un problème oculovisuel connu ont été analysées séparément. Nous avons utilisé le test de $t$ de Student et le test du chi-carré avec un seuil de signification statistique de 0,05. Résultats : En tout, 29,3\% des participants atteints de la MP par rapport à 7,3\% de ceux qui n'en étaient pas atteints avaient un score de 21 ou plus au CISS-15 ( $\mathrm{p}=0,001)$. Parmi les participants qui avaient un problème oculovisuel connu, 39,1\% de ceux qui étaient atteints de la MP par rapport à 19,1\% de ceux qui n'en n'étaient pas atteints avaient un score de 21 ou plus au CISS-15 ( $\mathrm{p}=0,01)$. Conclusions : La prévalence de symptômes visuels de type IC est plus élevée chez les individus atteints de la MP par rapport à ceux qui n'en sont pas atteints, qu'ils aient ou non un problème oculovisuel coexistant. Ces résultats suggèrent que la MP elle-même comporte un risque plus élevé de symptomatologie visuelle. Ces résultats soulignent également l'importance de procéder régulièrement à des examens des yeux chez les patients atteints de la MP.

Keywords: Convergence Insufficiency Symptom Survey Questionnaire, convergence insufficiency-type symptomatology, Parkinson's disease, prevalence

doi:10.1017/cjn.2017.39

Can J Neurol Sci. 2017; 44: 562-566

\section{INTRODUCTION}

Patients with Parkinson's disease (PD) have a variety of nonmotor symptoms that are becoming more recognized. ${ }^{1}$ Among these are such oculovisual symptoms as dry eyes, ${ }^{2}$ difficulty reading and double vision, ${ }^{1,3}$ which can affect quality of life in PD patients. Alterations in some visual functions have also been

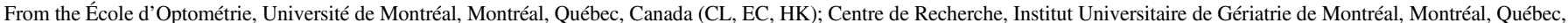

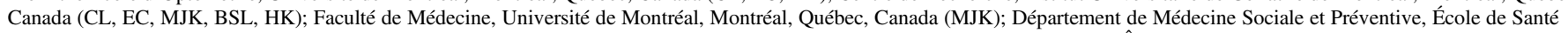

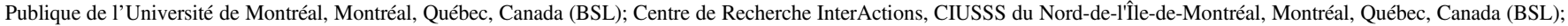

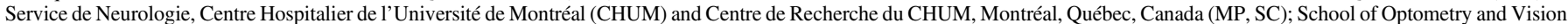
Science, University of Waterloo, Waterloo, Ontario, Canada (ELI); Department of Neurology, Montreal General Hospital, McGill University, Montréal, Québec, Canada (RBP). Received September 13, 2016. Final Revisions Submitted December 20, 2016. Date of Acceptance January 8, 2017.

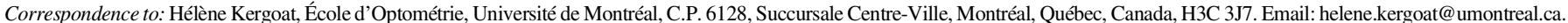


documented in PD, among which is convergence insufficiency (CI), a decreased ability to converge both eyes on an object located at a near distance. ${ }^{2}$ When present, CI can lead to blurred vision, tearing, ocular fatigue and double vision, and make it difficult or impossible for a person to read comfortably. This can be detrimental to many aspects of a person's life in modern countries, where the ability to read efficiently permeates the educational, working or even recreational environments.

Over the last two decades, a few studies have addressed CI-type symptomatology in individuals with $\mathrm{PD}^{2-6}$ The CI-related symptoms most frequently cited in PD were difficulty reading and diplopia. All of these studies, however, were conducted on limited numbers of participants, and none used a questionnaire developed and validated for CI. Our objective was to estimate the prevalence of CI-type symptomatology, in a systematic fashion, in a large population of individuals with $\mathrm{PD}$, compared to age-matched controls.

\section{Methods}

This study was conducted in collaboration with the Institut Universitaire de Gériatrie de Montréal (IUGM), the Centre Hospitalier de l'Université de Montréal (CHUM) and the Montreal General Hospital (MGH). The study protocol was approved by the research ethics committee of each of the three hospitals, and the study was conducted according to the Declaration of Helsinki. Participants signed an informed consent in accordance with the requirements of the various ethics committees.

A total of 300 participants $\geq 50$ years of age with a clinical diagnosis of PD were recruited from the movement disorder clinics (MDCs) of the neurology departments at the CHUM and the MGH (Figure 1). They were each matched for age ( \pm 5 years) and opposite sex to a control participant without PD. Opposite sex was used in trying to facilitate recruitment in case spouses would be interested in participating and knowing that a gender-related prevalence of CI had not been documented. ${ }^{7}$ A control was chosen among the spouse, family or friends of each participant with PD, and if none was found, the control was then recruited from the bank of participants at the IUGM. A few controls had to be recruited from a third alternative source, that is, the Clinique Universitaire de la Vision de l'Université de Montréal. The matching was done with a spouse $(20.0 \%)$, a family member $(0.3 \%)$ or another unrelated adult $(79.7 \%)$.

A review of clinical charts excluded individuals where binocular dysfunction other than CI (e.g., strabismus), known ocular disease/decreased visual acuity (e.g., glaucoma, age-related macular degeneration, amblyopia), other forms of neurodegenerative disease (e.g., Huntington's disease, dementia) or diseases likely to affect the extraocular muscles (e.g., Graves' thyroid disease, myasthenia gravis) or visual function (e.g., diabetes) were reported.

Individuals who met the study criteria based on their clinical chart review were contacted by mail and provided the following documents: a letter from a research neurologist explaining the study, ethics documents including information and the consent form, and answer codes for the Convergence Insufficiency Symptom Survey (CISS-15) questionnaire. Approximately 10 days later, the research assistant (RA) called each individual to answer any questions and determine if they were interested in taking part in the study. If individuals did not want to participate, no other contacts were made. If a person was interested in participating, he/she was first allowed to ask any questions related to the study, and then was given the choice to answer the phone questionnaires right away or at any other convenient time. The participant was asked to sign the consent form and mail it back to the research team, according to each ethics committee's requirements.

Phone interviews lasted about 30 minutes on average. Four questionnaires were filled out over the phone by the RA, in the following order: (1) the Adult Lifestyles Function Interview (ALFI), (2) an ocular history, (3) a general health questionnaire, and (4) the CISS-15. The first three questionnaires were employed to further assess the eligibility of the study participants. The ALFI is a telephone-administered version of the Mini-Mental State Examination (MMSE), which comprises 22 items aimed at screening for cognitive impairment. ${ }^{8}$ We designated a score below 14 as an exclusionary criterion. ${ }^{9}$ The ocular history and general health questionnaires were developed by the clinician/researcher specialists on our team and designed to ensure that the conditions

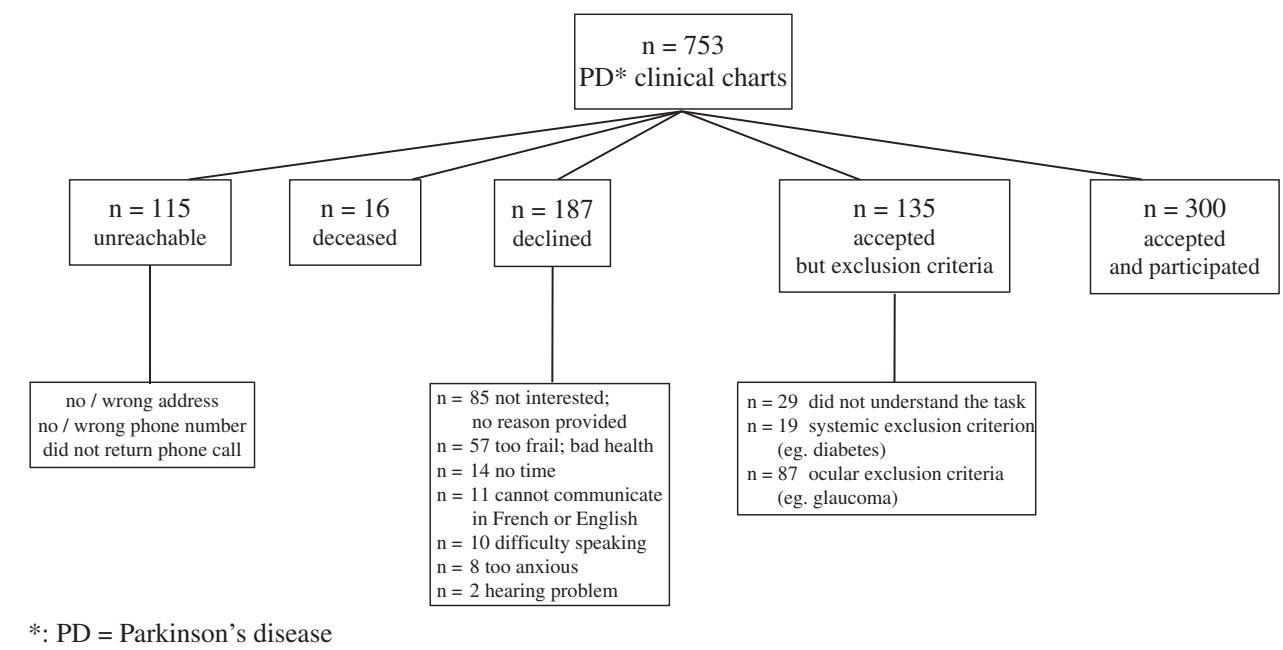

Figure 1: Recruitment of Parkinson's disease participants. 
specified by our inclusion/exclusion criteria were met. The CISS15 questionnaire $^{10}$ was designed to estimate the frequency and severity of CI symptoms and has been shown to be a valid and reliable instrument for $\mathrm{CI}$ treatment outcomes. ${ }^{11}$ It contains 15 items with a 5-digit scale from 0 to 4 . The response to each item expresses the frequency of symptom occurrence $(0=$ never, $4=$ always), and the potential total score, obtained by adding the individual response scores, ranges from 0 to 60 , with higher scores indicating greater symptom severity. A score of 21 has been shown to distinguish between symptomatic $(\geq 21)$ and asymptomatic $(<21)$ individuals, ${ }^{11}$ and so it served as the cutoff for CItype symptomatology in this study. All individuals who consented to participate were asked to answer the four questionnaires over the phone. Some had to be excluded from the main study because they indicated the presence of a binocular dysfunction other than CI or another ocular disease. Their data were kept and entered into a different Excel spreadsheet.

The statistical average differences and percentage differences between two independent groups were respectively determined using Student's $t$ test, with the chi-square level of significance set at 0.05 .

\section{RESUlTS}

The PD group included 121 women and 179 men with an average age of $67.3 \pm 8.9$ years, while the control group comprised 179 women and 121 men with an average age of $67.2 \pm 8.7$ years $(p>0.05)$. The participants with PD had an average of $2.9 \pm 1.7$ diseases and were taking $5.1 \pm 2.8$ medications (including $2.3 \pm 1.1$ PD-related medications), while the controls had an average of $1.6 \pm 1.4$ diseases and were taking $2.1 \pm 2.2$ medications $(p<0.001)$. The mean duration of PD was $8.4 \pm 5.9$ years. The group average score on the ALFI was $19.5 \pm 2.3$ for PD participants and $20.3 \pm 1.9$ for controls $(p=0.001)$. The group average score on the CISS-15 was $15.7 \pm 9.3$ for PD participants and $10.3 \pm 7.0$ for controls $(p=0.001)$. Some $29.3 \%(n=88)$ of PD participants and $7.3 \%(n=22)$ of controls $(p=0.001)$ had scores on the CISS-15 of $\geq 21$.

A total of 87 participants with (36 women) and 94 without (68 women) PD were excluded from the main study for known ocular disease ( $n=51 \mathrm{PD}, n=57$ controls) or a binocular vision anomaly other than CI ( $n=36 \mathrm{PD}, n=37$ controls) (Figure 2). The average age was $70.5 \pm 9.7$ years for PD participants and $70.7 \pm 8.9$ years for the controls $(p>0.05)$. The participants with PD had an average of $3.8 \pm 2.0$ diseases and were taking $5.9 \pm 2.6$ medications (including 2.3 \pm 1.1 PD-related medications), while the controls had an average of $2.0 \pm 1.9$ diseases and were taking $2.5 \pm 2.0$ medications $(p<0.01)$. The mean duration of PD was $9.0 \pm 6.3$ years. The group average score on the ALFI was $18.9 \pm 2.4$ for PD participants and $20.1 \pm 1.8$ for controls $(p=0.001)$. The group average score on the CISS-15 was $19.3 \pm 11.2$ for PD participants and 13.7 \pm 9.2 for controls $(p=0.001)$. A score on the CISS-15 of $\geq 21$ was obtained for $39.1 \%(n=34)$ of participants with and $19.1 \%(n=18)$ without $\operatorname{PD}(p=0.01)$.

An analysis of individual CISS symptoms in participants with positive CI symptomatology revealed that "eyes feel tired" and "eyes feel uncomfortable" when reading or doing close work stood out the most for PD and non-PD participants (Table 1). Those that emerged least were "headache" for "included/excluded" PD and "included" non-PD participants, and "double vision" for "excluded" non-PD participants.

\section{DISCUSSION}

The findings of our study indicate that CI-type visual symptomatology: (1) is higher in PD than in non-PD participants; (2) remains higher in PD versus non-PD participants, for those

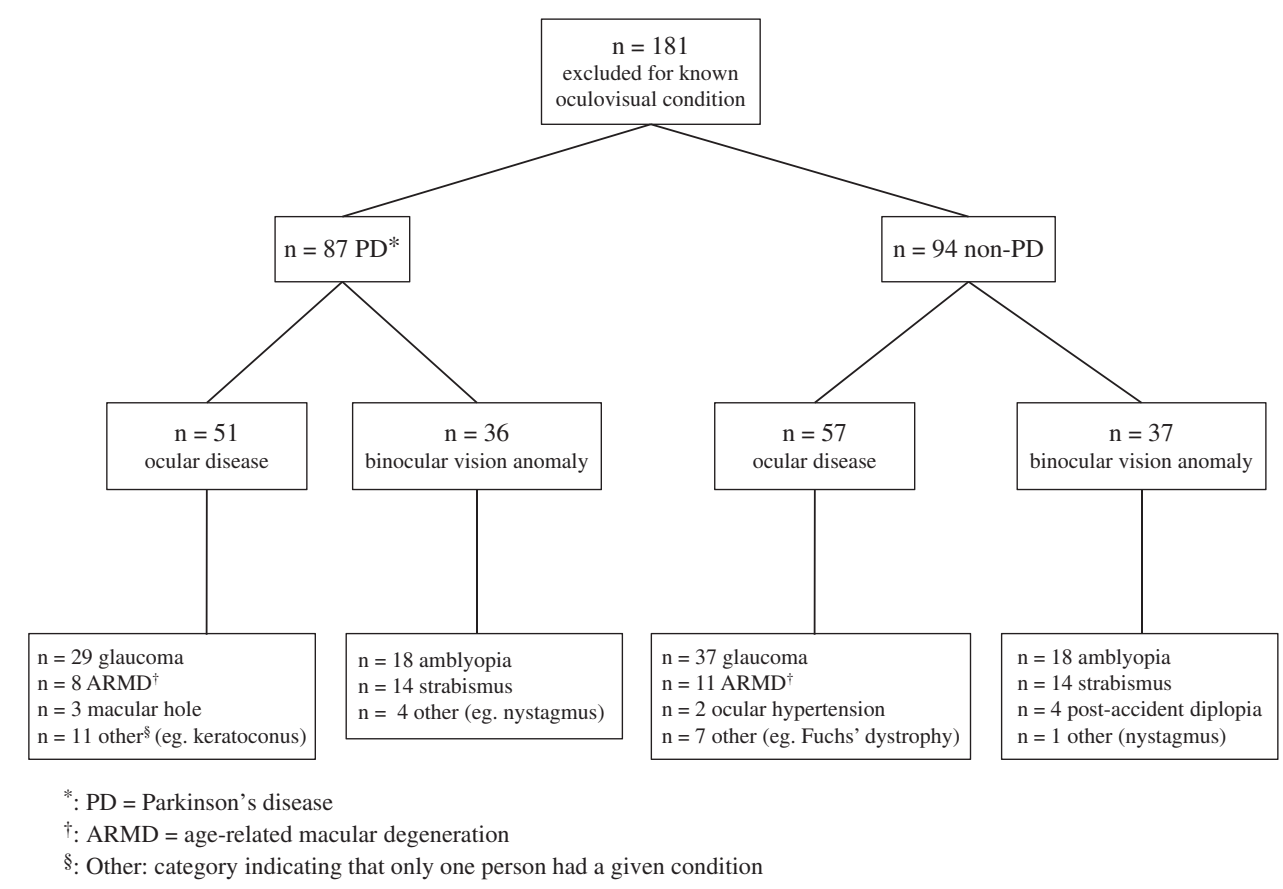

Figure 2: Oculovisual conditions excluding participants. 
Table 1: Occurrence/severity of the most and least frequent symptoms in included/excluded participants having subjective convergence insufficiency

\begin{tabular}{|c|c|c|}
\hline & \multicolumn{2}{|c|}{ PD participants } \\
\hline & $\begin{array}{c}\text { Included } \\
\text { (Subjective CI; } \boldsymbol{n}=\mathbf{8 8} \text { ) }\end{array}$ & $\begin{array}{c}\text { Excluded } \\
\text { (Subjective CI; } n=34)\end{array}$ \\
\hline \multicolumn{3}{|l|}{ Most frequent symptoms } \\
\hline $\begin{array}{l}\text { Eyes feel tired: } \\
\%(n) / \text { severity score }\end{array}$ & $95.5(84) / 2.26$ & $100.0(34) / 2.76$ \\
\hline $\begin{array}{l}\text { Eyes feel uncomfortable: } \\
\%(n) / \text { severity score }\end{array}$ & $98.9(87) / 2.36$ & $100.0(34) / 2.79$ \\
\hline \multicolumn{3}{|l|}{ Least frequent symptom } \\
\hline \multirow[t]{3}{*}{$\begin{array}{l}\text { Headache: } \\
\%(n) / \text { severity score }\end{array}$} & $39.8(35) / 0.66$ & $41.2(14) / 0.91$ \\
\hline & \multicolumn{2}{|c|}{ Controls } \\
\hline & $\begin{array}{c}\text { Included } \\
\text { (Subjective CI; } n=22)\end{array}$ & $\begin{array}{c}\text { Excluded } \\
\text { (Subjective CI; } n=18)\end{array}$ \\
\hline \multicolumn{3}{|l|}{ Most frequent symptoms } \\
\hline $\begin{array}{l}\text { Eyes feel tired: } \\
\%(n) / \text { severity score }\end{array}$ & $100(22) / 2.68$ & $100(18) / 2.78$ \\
\hline $\begin{array}{l}\text { Eyes feel uncomfortable: } \\
\%(n) / \text { severity score }\end{array}$ & $90.9(20) / 2.23$ & $100(18) / 2.67$ \\
\hline \multicolumn{3}{|l|}{ Least frequent symptom } \\
\hline $\begin{array}{l}\text { Headache: } \\
\%(n) / \text { severity score }\end{array}$ & $40.9(9) / 0.91$ & \\
\hline $\begin{array}{l}\text { Double vision: } \\
\%(n) / \text { severity score }\end{array}$ & & $44.4(8) / 1.00$ \\
\hline
\end{tabular}

$\mathrm{CI}=$ convergence insufficiency $\mathrm{PD}=$ Parkinson's disease.

having a known oculovisual condition; and (3) is higher in PD and non-PD participants having versus not having a known oculovisual condition. Overall, these results indicate that having a known oculovisual condition is accompanied by a high prevalence of visual symptoms, and they further suggest that having PD per se places individuals with the disease at higher risk for visual symptomatology.

The prevalence of CI-type visual symptomatology in individuals with PD (29.3\%) was found to be four times greater than for those without PD (7.3\%) and two times higher in PD (39.1\%) versus non-PD (19.1\%) for individuals with a preexisting oculovisual condition. These results are rather strong and deserve some interpretation. It is important to point out that the CISS-15 questionnaire employed in the present study was originally designed by experts to address the symptoms most likely to be present in individuals having a diagnosis of CI, and to serve as an outcome measure of success for $\mathrm{CI}$ treatment. In other words, this questionnaire was to be used in people already with a diagnosis of $\mathrm{CI}$ and was not meant to serve as a screening tool for CI. Knowing this limitation, the CISS-15 questionnaire was utilized here since it was the only existing validated tool to at least enquire about "CI-type" symptoms that could be used in a large number of participants. The similarity of symptoms found in CI and in other oculovisual conditions could have increased the prevalence of symptoms found in the present study. The elevation of CISS scores in those having a known oculovisual condition is consistent with this. The present results confirm those obtained in our previous report ${ }^{12}$ indicating that "eyes feel tired or uncomfortable while reading or doing close work" is a more prevalent/severe symptom than "double vision" in that population, and they suggest that this item could be added in non-motor screens to better identify PD individuals with vision problems. It is also important to point out that our data showing a higher prevalence of CI-type symptomatology in PD does not indicate that a diagnosis of CI is more prevalent in PD. Further research that would include a complete eye exam is needed to address this issue and has been pursued in view of the strength of the results obtained here. Although the limited resources available for the present study prevented the provision of an eye exam for all participants, we have been able to perform eye exams in a subset of $80 \mathrm{PD}$ and 80 non-PD participants. Results from this research have shown that a clinical diagnosis of $\mathrm{CI}$ is in fact more prevalent in PD (43.8\%) versus non-PD (16.3\%) participants. ${ }^{12}$ Taken together, these prevalence data underline the importance of evaluating oculovisual symptomatology and $\mathrm{CI}$ in individuals with PD. Oculovisual symptomatology being particularly prevalent in $\mathrm{PD}$, it is important to provide these individuals with regular eye exams and treat any underlying oculovisual condition if at all possible. If symptoms were to be linked with a diagnosis of $\mathrm{CI}$ in patients experiencing significant discomfort and decreased quality of life, then it could be possible to offer them some form of treatment, such as prism or orthoptic therapy. These therapies would have to be decided based on the stability of the clinical findings, however, and if judged of potential benefit, would have to be well-explained and reserved to highly motivated patients, since they are known to work for older individuals ${ }^{13-15}$ but have not been formally evaluated in PD.

Another limitation to this study is that we could not stage the severity of PD since the Unified Parkinson's Disease Rating Scale scores or Hoehn and Yahr staging were not available. Although this does not allow a comparison between severity of $\mathrm{PD}$ and severity of CI-type symptomatology, it does not change the results that indicate a higher prevalence of CI-type symptomatology in PD versus non-PD individuals. In addition, using clinical charts to identify and recruit PD participants may have affected the population representativity of our sample, but it would be difficult to offer an opinion on the direction or magnitude of any potential selection bias. However, the strength of these data suggests that similar results would likely have been obtained in another PD population recruited under a different mode of selection.

Despite these acknowledged limitations, the higher prevalence of symptoms found in those having PD certainly stresses the impact the disease has on the oculovisual system. It has been reported that ocular changes take place early on in the course of $\mathrm{PD}$, likely a result of the disease itself. ${ }^{2}$ Our results further suggest that particular care should be provided to patients with PD during an eye exam, in order to verify the extent of their symptoms and address them if at all possible. Similarly, as mentioned by Chaudhuri et al., ${ }^{1}$ neurologists should also pay special attention to non-motor symptoms, including the oculovisual ones, in the care of their PD patients. This is particularly important knowing that PD medications can have a positive effect on visual function. ${ }^{6,16}$ To that effect, it is worth mentioning that daytime somnolence has been linked with diplopia. ${ }^{3}$ The authors suggested that drowsiness may alter the ability to maintain fusion, ${ }^{3}$ a condition that may or may not be helped by PD medications, depending on whether the drowsiness is induced by a symptomatic undiagnosed binocular vision problem or the medication itself, or is due directly to the 
disease process itself (i.e., degeneration of wake-promoting nuclei). It is interesting to add that the issue of how ocular pathology contributes to disability in PD has been raised in a review paper addressing the retina in PD. ${ }^{17}$ Although our results cannot provide an answer to that question, they certainly demonstrate that symptoms are higher in the presence of an ocular pathology or a visual dysfunction, and they reinforce the importance of pursuing research aimed at better understanding vision in PD.

In conclusion, our data have shown that convergence insufficiency-type symptomatology is higher in individuals with Parkinson's disease having or not having a concurrent visual dysfunction or ocular pathology. Our results further stress the importance of providing regular eye exams for individuals affected by this disease.

\section{ACKNOWLEDGMENTS}

This work was supported by the Comité Aviseur pour la Recherche Clinique (CAREC) at the IUGM, the Canadian Institutes of Health Research (CIHR, MOP-123462) and the Canadian Optometric Education Trust Fund (COETF). These funding sources had no involvement in the research performed or the research report. The authors thank the team of neurologists and personnel at the movement disorder clinic; the "Gestion de l'Information" and the "Archive" departments of the CHUM; and the team of neurologists and personnel at the neurology department of the MGH; as well as Milena Dimitrova.

\section{CONFLICTS OF INTEREST}

The authors have no conflicts of interest to report.

\section{Statement of Authorship}

Conception of the project (EC, MJK, BSL, MP, ELI, HK); data acquisition (CL, EC); expertise in various aspects of participant recruitment (MJK, MP, ELI, RP, SC, HK); writing and critical review of the manuscript (all coauthors); and statistical analyses (BSL).

\section{Disclosures}

Marie-Jeanne Kergoat has the following disclosures: CARECIUGM: grant recipient, research grant; CIHR: grant recipient, research grant; Alzheimer Society of Canada: grant recipient, research grant; FRSQ-Pfizer: grant recipient, research grant; CCNA, grant recipient, research grant.

Estefania Chriqui, Bernard-Simon Leclerc and Caroline Law do not have anything to disclose.

Michel Panisset has the following disclosures: Merz: advisory board, honoraria; Allegan: advisory board, honoraria; Medtronic: independent investigator, research support.

Elizabeth Irving has the following disclosures: CIHR, co-investigator, research grant; NSERC, principal investigator; Canadian Optometric Education Trust Fund: research grant; University of Waterloo Research Incentive Fund: research grant; CIMVHR, research contract.

Ronald Postuma has the following disclosures: Roche: consultant, honoraria; CIHR, grantee, grant; FRSQ, grantee, grant; Parkinson Society of Canada: grantee, grant; Michael J. Fox Foundation: grantee, grant; Weston Garfield Foundation: grantee, grant; Biogen: consultant, honoraria; Biotie: consultant, honoraria; Teva: speaker, honoraria; Webster: grantee, grant.
Sylvain Chouinard has the following disclosures: Abbie: advisor, consulting fees; Merz: advisor, consulting fees; Allergan: advisor, consulting fees.

Hélène Kergoat has the following disclosures: COETF: grant recipient, research grant; CAREC-IUGM: grant recipient, research grant; NSERC, grant recipient, research grant; CIHR, grant recipient, research grant; Alzheimer Society of Canada: grant recipient, research grant.

\section{REFERENCES}

1. Chaudhuri KR, Martinez-Martin P, Schapira AH, et al. International multicenter pilot study of the first comprehensive self-completed nonmotor symptoms questionnaire for Parkinson's disease: the NMSQuest study. Mov Disord. 2006;21(7): 916-23.

2. Biousse V, Skibell BC, Watts RL, Loupe DN, Drews-Botsch C, Newman NJ. Ophthalmologic features of Parkinson's disease. Neurology. 2004;62(2):177-80.

3. Archibald NK, Clarke MP, Mosimann UP, Burn DJ. Visual symptoms in Parkinson's disease and Parkinson's disease dementia. Mov Disord. 2011;26(13):2387-95. Epub ahead of print Sep 27.

4. Repka MX, Claro MC, Loupe DN, Reich SG. Ocular motility in Parkinson's disease. J Pediatr Ophthalmol Strabismus. 1996;33(3): 144-147.

5. Lepore FE. Parkinson's disease and diplopia. Neuroophthalmology. 2006;30(2-3):37-40.

6. Almer Z, Klein KS, Marsh L, Gerstenhaber M, Repka MX. Ocular motor and sensory function in Parkinson's disease. Ophthalmology. 2012;119(1):178-82. Epub ahead of print Sep 29, 2011. https://www.ncbi.nlm.nih.gov/pmc/articles/PMC3251710/. Accessed February 19, 2017.

7. Scheiman M, Gwiazda J, Li T. Non-surgical interventions for convergence insufficiency (review). Cochrane Database Syst Rev. 2011;3:CD006768. https://www.ncbi.nlm.nih.gov/ pmc/articles/PMC4278667/. Accessed February 19, 2017.

8. Roccaforte WH, Burke WJ, Bayer BL, Wengel SP. Validation of a telephone version of the Mini-Mental State Examination. J Am Geriatr Soc. 1992;40(7):697-702.

9. Quail JM, Addona V, Wolfson C, Podoba JE, Lévesque LY, Dupuis J. Association of unmet need with self-rated health in a community-dwelling cohort of disabled seniors 75 years of age and over. Eur J Ageing. 2007;4(1):45-55.

10. Scheiman M, Mitchell GL, Cotter S, et al. The Convergence Insufficiency Treatment Trial: design, methods, and baseline data. Ophthalmic Epidemiol. 2008;15(1):24-36. https://www. ncbi.nlm.nih.gov/pmc/articles/PMC2782898/. Accessed February 19, 2017.

11. Rouse MW, Borsting EJ, Mitchell GL, et al. Validity and reliability of the revised Convergence Insufficiency Symptom Survey in adults. Ophthalmic Physiol Opt. 2004;24(5):384-90.

12. Irving EL, Chriqui E, Law $\mathrm{C}$, et al. Prevalence of convergence insufficiency in Parkinson's disease. Mov Disord Clin Pract. 2016. Epub ahead of print Nov 20.

13. Teitelbaum B, Pang Y, Krall J.. Effectiveness of base in prism for presbyopes with convergence insufficiency. Optom Vis Sci. 2009;86(2):153-6.

14. Birnbaum MH, Soden R, Cohen AH. Efficacy of vision therapy for convergence insufficiency in an adult male population. J Am Optom Assoc. 1999;70(4):225-32.

15. Wick B. Vision training for presbyopic nonstrabismic patients. Am J Optom Physiol Opt. 1977;54(4):244-7.

16. Racette BA, Gokden M, Tychsen L, Perlmutter JS. Convergence insufficiency in idiopathic Parkinson's disease responsive to levodopa. Strabismus. 1999;7(3):169-74.

17. Archibald NK, Clarke MP, Mosimann UP, Burn DJ. The retina in Parkinson's disease. Brain. 2009;132(Pt 5):1128-45. Epub ahead of print Mar 31. https://academic.oup.com/brain/ article-lookup/doi/10.1093/brain/awp068. Accessed February 19, 2017. 